\title{
SSynthesis
}

International Scientific Conference of IT and Business-Related Research

\section{MODEL ORGANIZACIONE SOCIJALIZACIJE}

\section{ORGANIZATIONAL SOCIALIZATION MODEL}

\author{
Lepa Babić ${ }^{1}$, Boris Kordić ${ }^{2}$, Jovana Babić ${ }^{3}$ \\ ${ }^{1}$ Poslovni fakultet u Beogradu, Univerzitet Singidunum, Danijelova 32, Beograd, Republika Srbija \\ ${ }^{2}$ Fakultet bezbednosti, Univerzitet u Beogradu, Gospodara Vučića 50, Beograd, Republika Srbija \\ ${ }^{3}$ Master psihologije, Filozofski fakultet Univerzitet u Beogradu
}

\begin{abstract}
Apstrakt:
Proces kojim se novozaposleni pretvaraju u funkcionalne članove organizacije je organizaciona socijalizacija. Taj proces polazi od karakteristika individue $\mathrm{i}$ karakteristika same organizacije te se individualnom $\mathrm{i}$ institucionalnom socijalizacijom dolazi do dve vrtse ishoda; ishoda koji su povezani sa individualnim doprinosom uspehu organizacije (radni učinak) i onih koji doprinose organizacionoj klimi i kulturi (integracija u kolektiv). Navedeni elementi predstavljaju osnovne elemente modela organizacione socijalizacije. Autori se u ovom radu bave istraživanjem povezanosti između oblika organizacione socijalizacije i indikatora socijalizovanosti novozaposlenih u organizacijama na teritoriji Srbije. Izdvojena su tri oblika organizacione socijalizacije (uticaj edukacije, planirana socijalizacija i spontana socijalizacija) i tri indikatora socijalizovanosti novozaposlenih (zadovoljstvo poslom i kolektivnom, stres i apsentizam i uključenost i uspeh u radu). $\mathrm{Na}$ ispitanom uzorku se najizraženija povezanost pokazala između spontane socijalizacije i indikatora socijalizovanosti novozaposlenih. Zaključak je da su starije kolege i nadređeni značajan izvor informacija i konkretne pomoći i podrške koji doprinosi da novozaposleni ovladaju zadacima i radnom ulogom. Ovakvi nalazi su u skladu sa organizacionom kulturom koja preovladava na prostorima Srbije i za koju su karakteristične vrednosti usmerene na socijalne odnose. Stoga model organizacione socijalizacije za preduzeća u Srbiji trebalo bi da inkorporira specifičnosti nacionalne i organizacione kulture kombinujući osnovne elemente modela organizacione socijalizacije.
\end{abstract}

\section{Ključne reči:}

spontana socijalizacija, planirana socijalizacija, indikatori socijalizovanosti novozaposlenih, taktike socijalizacije, integracija u kolektiv.

\section{UVOD}

Organizaciona socijalizacija predstavlja proces kojim se novozaposleni pretvaraju u funkcionalne članove organizacije (Kordić \& Babić, 2014) što u sebi uključuje učenje vrednosti i normi (Van Maanen, 1976) i sticanje potrebnih znanja, veština i ponašanja koja ih pretvaraju u dobro uklopljene članove organizacije (Bauer \& Erdogan, 2010). Reč proces podrazumeva trajanje u vremenu tako da modeli koji prikazuju proces organizacije razlikuju početno stanje (karakteristike individue i karakteristike organizacije), proces koji se odvija tokom susreta individue i organizacije i ishode tog procesa. Tokom procesa socijalizacije organizacije često upotrebljavaju određene mehanizme kako bi pospešile socijalizaciju, a to se naziva taktike socijalizacije.

\section{Abstract:}

Organizational socialization is the process by which newcomers become functional members of an organization and get acclimated to the culture of a new workplace. This process starts with the characteristics of an individual and characteristics of an organization itself, which is why individual and institutional socialization lead to two possible outcomes; those related to one's contribution to an organization's success ( performance) and those contributing to the organizational climate and culture (collective integration). The given elements are the key elements of the organisational socialisation model. The authors examine the connection and correlation between the forms of organizational socialization and indicators of socialization of newcomers in organizations on the territory of the Republic of Serbia. The three main forms of organizational socialization are highlighted (impact of education, planned socialization and spontaneous socialization) as well as three indicators of socialization of newcomers (job and collective satisfaction, stress and absenteeism, and involvement and success at work). The surveyed sample shows the highest correlation between spontaneous socialization and socialization indicators of newcomers. Thus, the conclusion can be made that older colleagues and superiors are an important source of information and support that enables the newcomers to successfully complete their tasks and work duties. Such findings are in accordance with the prevailing organizational culture on the territory of the Republic of Serbia and whose characteristic values are directed towards social relations. Therefore, the organizational socialization model for enterprises in Serbia should incorporate the specifics of national and organizational culture by combining the basic elements of organizational socialization model.

\section{Key words:}

spontaneous socialization, planned socialization, indicators of socialization of newcomers, socialization tactics, collective socialization.

Uobičajeno se taktike socijalizacije dele u dve kategorije (Jones, 1986): individualnu i institucionalnu socijalizaciju. Individualna socijalizacija podrazumeva da pojedinac počinje sa poslom odmah i postepeno se uklapa u radnu sredinu, dok institucionalna socijalizacija podrazumeva da postoje definisani programi koje novozaposleni prolaze. Kod individualne socijalizacije novozaposleni sami traže potrebne informacije i podstiču međusobne odnose sa kolegama, dok su kod institucionalne socijalizacije vođeni kroz proces socijalizacije po unapred utvrđenom planu i programu. Ishodi organizacione socijalizacije se posmatraju kroz razne indikatore koji imaju za cilj da utvrde u kojoj meri je došlo do poklapanja između individue i organizacije. U literaturi se najčešće navode sledeći indikatori: radna efikasnost ili ovladanost zadatkom, tendencija za otkazom (Cooper-Thomas \& Anderson, 2005; Kammeyer-Mueller et al., 2013), jasno- 
ća radne uloge (Jokisaari \& Nurmi, 2009; Kammeyer-Mueller \& Wanberg, 2003), zadovoljstvo poslom (Jokisaari \& Nurmi, 2009; Cooper-Thomas \& Anderson, 2005), posvećenost organizaciji (Allen \& Rhoades, 2013; Kammeyer-Mueller \& Wanberg, 2003), uključenost u posao (Nigah et al, 2012), stres (Bolino et al., 2010), integracija u kolektiv i poznavanje programskih politika (Kammeyer-Mueller \& Wanberg, 2003). S obzirom da je cilj organizacije uspešno poslovanje ishodi se mogu grupisati u dve osnovne kategorije: oni koji su povezani sa individualnim doprinosom uspehu organizacije (radni učinak) i oni koji doprinose organizacionoj klimi i kulturi (integracija u kolektiv). Pomenuti elementi predstavljaju osnovne elemente modela organizacione socijalizacije (v. Tabela 1 ).

\begin{tabular}{|c|c|c|}
\hline Početno stanje & Proces & Ishod \\
\hline Individua & $\begin{array}{c}\text { Individualna } \\
\text { socijalizacija }\end{array}$ & $\begin{array}{c}\text { Integracija u } \\
\text { kolektiv }\end{array}$ \\
\hline Organizacija & $\begin{array}{c}\text { Institucionalna } \\
\text { socijalizacija }\end{array}$ & Radni učinak \\
\hline
\end{tabular}

Tabela 1. Osnovni elementi modela organizacione socijalizacije.

Kombinujući osnovne elemente modela organizacione socijalizacije sa rezultatima istraživanja koje su autori sproveli na teritoriji Srbije (Kordić \& Babić, 2014) predložićemo model organizacione socijalizacije specifičan za područje Srbije.

\section{REZULTATI I DISKUSIJA}

$\mathrm{Na}$ osnovu istraživanja povezanosti između oblika organizacione socijalizacije i indikatora socijalizovanosti novozaposlenih u organizacijama na teritoriji Srbije (Kordić \& Babić, 2014) izdvojena su tri oblika organizacione socijalizacije i tri indikatora socijalizovanosti novozaposlenih. U oblike organizacione socijalizacije spadaju: Uticaj edukacije, planirana socijalizacija i Spontana socijalizacija. Uticaj edukacije govori o aktivnostima koje organizacija preduzima kako bi kroz dodatnu edukaciju obučila zaposlene i doprinela prilagođavanju radnoj sredini i izgradnji dobrih kolegijalnih odnosa. Planirana socijalizacija govori o konkretnim merama koje organizacija preduzima kako bi bolje socijalizovala zaposlene, kao što su: mentorski rad, priručnici, simulacije, rotacije i obuke na konkretnom radnom mestu. Spontana socijalizacija govori o spremnosti i ulaganju kolega i nadređenih da pomognu novozaposlenima u uklapanju u socijalnu mrežu i prilagođavanju na radno okruženje.

U indikatore socijalizovanosti novozaposlenih spadaju:

- Zadovoljstvo poslom i kolektivom,

- Stres i apsentizam i

- Uključenost i uspeh u radu.

Zadovoljstvo poslom i kolektivom govori o pozitivnim osećanjima i zadovoljstvu vezano za radno okruženje, radnu ulogu, mesto u organizaciji, te međuljudske odnose sa kolegama i nadređenima. Stres i apsentizam govore o pojačanom stresu i odsustvu sa posla zbog problema na poslu usled nedovoljnih kompetencija, neadekvatnog tretmana nadređenih i loših međuljudskih odnosa. Uključenost i uspeh u radu govori o odgovornom odnosu prema radu koji podrazumeva postavljene ciljeve, poštovanje rokova, kvalitetno obavljanje posla, osećaj pune kompetentnosti, ulaganje svih potencijala i praćenje povratnih informacija. Zbog malog uzorka stres i apsentizam je slabo izražen i javlja se pojačano samo u jednoj organizaciji od tri koje su ušle u istraživanje, stoga ga isključujemo iz daljeg prikaza rezultata.

\begin{tabular}{|c|c|c|}
\hline & $\begin{array}{c}\text { Zadovoljstvo poslom i } \\
\text { kolektivom }\end{array}$ & $\begin{array}{c}\text { Uključenost i } \\
\text { uspeh u radu }\end{array}$ \\
\hline Uticaj edukacije & $.334\left(^{* *}\right)$ & $.302\left(^{* *}\right)$ \\
\hline $\begin{array}{c}\text { Planirana } \\
\text { socijalizacija }\end{array}$ & $.374\left(^{* *}\right)$ & $.235\left(^{*}\right)$ \\
\hline $\begin{array}{c}\text { Spontana } \\
\text { socijalizacija }\end{array}$ & $.623\left(^{* *}\right)$ & $.358\left(^{* *}\right)$ \\
\hline
\end{tabular}

** statistička značajnost na nivou 0.01

* statistička značajnost na nivou 0.05

Tabela 2. Povezanosti između oblika organizacione socijalizacije i indikatora socijalizovanosti.

U Tabeli 2. su prikazane povezanosti između oblika organizacione socijalizacije i indikatora socijalizovanosti. Na našem uzorku je najizraženija povezanost između spontane socijalizacije i indikatora socijalizovanosti novozaposlenih. To je u skladu sa organizacionom kulturom koja preovladava na prostorima Srbije i za koju su karakteristične vrednosti usmerene na socijalne odnose gde je briga, nega i održavanje odnosa sa kolegama na poslu važnija od samopotvrđivanja, takmičenja i radnog učinka (Babić \& Kordić, 2011). Postojeće osobenosti organizacione kulture u Srbiji povezane sa značajem socijalnih odnosa sve više postaju naglašene u literaturi o organizacionoj socijalizaciji na engleskom govornom području. Tako se ističe značaj međuljudskih odnosa za organizacionu socijalizaciju (Allen \& Rhoades, 2013; Kammeyer-Mueller et al., 2013), značaj socijalne podrške i integrisanosti u kolektiv za ukupno zadovoljstvo poslom (Anderson \& Thomas, 1996; Jokisaari \& Nurmi, 2009), kao i značaj socijalne podrške za zadovoljstvo poslom i posvećenost organizaciji (Luthans et al., 2007; Morrison, 2002).

Promene u organizacionoj kulturi preduzeća na teritoriji Srbije koja teže usklađivanju sa organizacionim kulturama razvijenog zapada najverovatnije idu u pravcu koji će se pokazati suprotan novim tendencijama. Ono što se danas u Srbiji propagira kao organizaciona kultura savremenih preduzeća zapada, na zapadu se već menja u novom pravcu. I dalje je krajnji cilj kojem se teži profit i, shodno tome, radni učinak. Međutim, analizirajući psihološki i radni kapital zaposlenog, socijalna podrška se pojavljuje kao medijator koji značajno utiče na radnu efikasnost i uključenost u rad (Nigah et al., 2012). Posebno je važan početni uticaj podrške nadređenih za usvajanje jasne radne uloge i ovladavanje radnim zadacima (Jokisaari \& Nurmi, 2009). Gledano na duge staze, socijalna podrška ima kontinuiran značaj za posvećenost organizaciji (Jokisaari \& Nurmi, 2009) i zadovoljstvo poslom (Anderson \& Thomas, 1996; Jokisaari \& Nurmi, 2009), dok se radni učinak ponaša relativno nezavisno nakon određenog perioda socijalizacije (Morrison, 2002).

Zaključak istraživanja na uzorku preduzeća iz Srbije jeste da su starije kolege i nadređeni značajan izvor informacija i konkretne pomoći i podrške koji doprinosi da novozaposleni ovladaju zadacima i radnom ulogom tokom dužeg vremenskog perioda, dok su edukacija i taktike socijalizacije karakteristične za planiranu socijalizaciju vremenski ograničenog trajanja i stoga slabijeg uticaja (Kordić \& Babić, 2014).

Model organizacione socijalizacije za preduzeća u Srbiji trebalo bi da sadrži specifičnosti nacionalne i organizacione kulture. Stoga smo ponudili model prikazan u Slici 1. koji predstavlja pojednostavljenu strukturu procesa koji prolaze novozaposleni u organizacijama na teritoriji Srbije. Pod uslovom da je procesom selekcije izabrana osoba koja optimalno odgovara traženim zahtevima za radno mesto, najvažniju ulogu u uklapanju u 


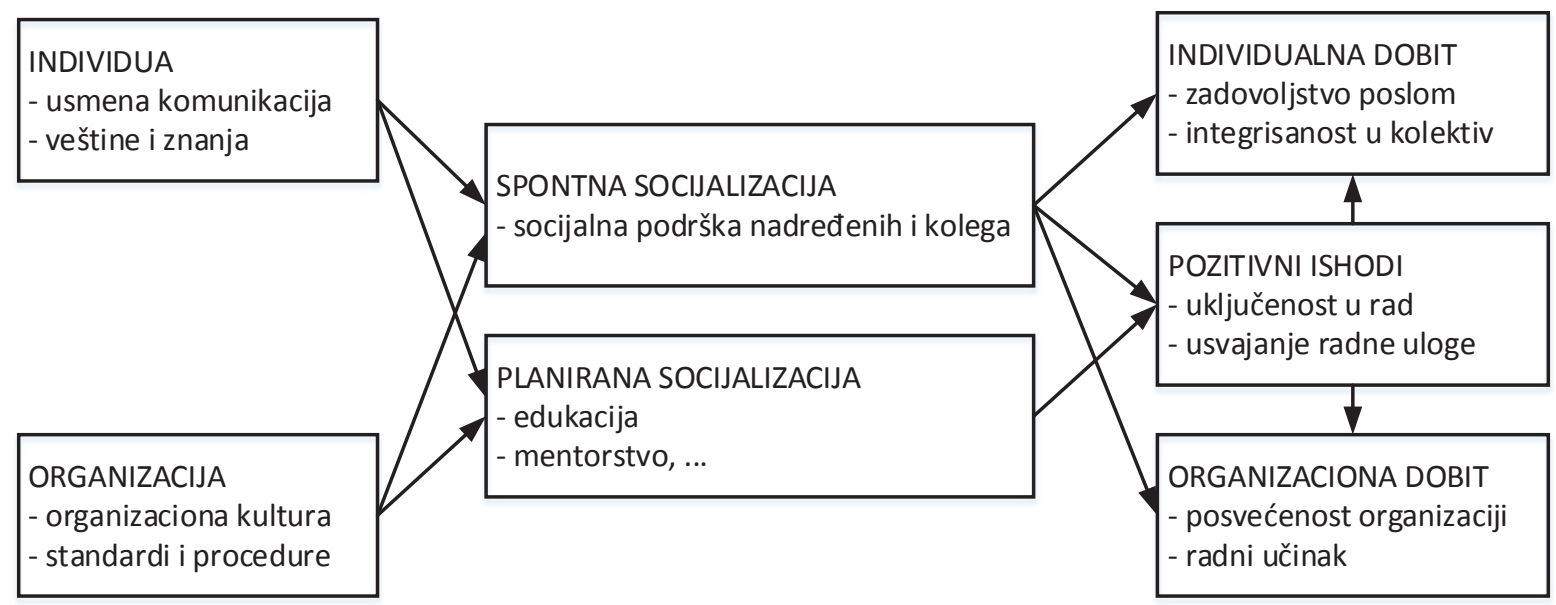

Slika 1. Model organizacione socijalizacije

radnu sredinu i socijalno okruženje ima spontana socijalizacija, a zatim i planirana socijalizacija. Taktike socijalizacije bi trebale da se baziraju na nalazima savremenih istraživanja o značaju socijalne podrške za integrisanje u kolektiv. U tom smislu se preporučuje, pored obuka koje približavaju standarde i procedure date organizacije novozaposlenom, da se prvenstveno koristi mentorski rad i podsticanje socijalne podrške nadređenih kao oblik planirane socijalizacije. Ovakav pristup će dovesti do pozitivnih ishoda socijalizacije olakšavajući novozaposlenom usvajanje radne uloge i uključivanje u rad. Lična dobit koju individua ima od pozitivnih ishoda socijalizacije jeste dobra integrisanost u kolektiv i zadovoljstvo poslom, dok organizacija ima dobit u radnom učinku zaposlenog i posvećenosti zaposlenog organizaciji.

\section{REZIME}

Kombinujući osnovne elemente modela organizacione socijalizacije sa rezultatima istraživanja socijalizacije u preduzećima u Srbiji predložen je model koji objašnjava procese koje novozaposleni prolaze u organizacijama na teritoriji Srbije. Pretvaranje novozaposlenih u funkcionalne članove organizacije počinje od karakteristika individue i karakteristika same organizacije. Pod uslovom da je procesom selekcije izabrana osoba koja optimalno odgovara traženim zahtevima za radno mesto, najvažniju ulogu u uklapanju u radnu sredinu i socijalno okruženje ima spontana socijalizacija, a zatim i planirana socijalizacija. U okviru spontane socijalizacije starije kolege i nadređeni predstavljaju značajan izvor informacija i konkretne pomoći i podrške koji doprinosi da novozaposleni ovladaju zadacima i radnom ulogom. Na prostorima Srbije preovladava organizaciona kultura za koju su karakteristične vrednosti usmerene na socijalne odnose gde su briga, nega i održavanje odnosa sa kolegama na poslu važniji od samopotvrđivanja, takmičarstva i radnog učinka. Spontana i planirana socijalizacija zajedno dovode do pozitivnih ishoda, a to su uključenost u rad i usvajanje radne uloge. Ovakvi ishodi donose individualnu dobit (dobra integrisanost u kolektiv i zadovoljstvo poslom) sa jedne strane i organizacionu dobit (radni učinak i posvećenost organizaciji) sa druge strane.
Napomene. Ovaj naučni rad je proistekao iz saradnje dva projekta: "Bezbednost i zaštita organizovanja i funkcionisanja vaspitno-obrazovnog sistema u Republici Srbiji (osnovna načela, principi, protokoli, procedure i sredstva)“, Ministarstvo nauke Republike Srbije, br. 47017, za period 2011-2015. godine, i "Unapređenje konkurentnosti Srbije u procesu pristupanja Evropskoj uniji", Ministarstvo nauke Republike Srbije, br. 47028, za period 2011-2015. godine.

\section{LITERATURA}

Allen, D.G., \& Rhoades, L.S. (2013). Perceived organizational support and embeddedness as key mechanisms connecting socialization tactics to commitment and turnover among new employees. Journal of Organizational Behavior, 34(3), 350-369.

Anderson, N., \& Thomas, H.D.C. (1996). Work group socialization. U M. A. West (Ed.), Handbook of work groups (pp. 423 -450). Chichester: Wiley.

Babić. L., \& Kordić, B. (2011). Nacionalna kultura i karijerni razvoj. Zbornik radova: VIII Naučni skup sa međunarodnim učešćem Sinergija 2011, 25. mart 2011. godine, Bijeljina, str. 250-265.

Bauer, T.N., \& Erdogan, B. (2010). Organizational socialization: The effective onboarding of new employees. U S. Zedeck i sar (Eds.), APA Handbook of industrial and organizational Psychology, 3, 51-64. Washington, DC: APA Press.

Bolino, M., Valcea, S. \& Harvey, J. (2010). Employee, manage thyself: The potentially negative implications of expecting employees to behave proactively. Journal of Occupational and Organizational Psychology, 83(2), 325-345.

Cooper-Thomas, H., \& Anderson, N. (2002). Newcomer adjustment: The relationship between organizational socialization tactics, information acquisition and attitudes. Journal of Occupational and Organizational Psychology, 75(4), 423-437

Jokisaari, M., \& Nurmi, J.E. (2009). Change in Newcomers' Supervisor Support and Socialization Outcomes After Organizational Entry. Academy of Management Journal, 52(3), 527-544. 
Jones, G.R. (1986). Socialization tactics, self-efficacy, and newcomers' adjustments to organizations. Academy of Management Journal, 29(2), 262-279.

Kammeyer-Mueller, J.D., \& Wanberg, C.R. (2003). Unwrapping the organizational entry process: Disentangling multiple antecedents and their pathways to adjustment. Journal of Applied Psychology, 88(5), 779-794.

Kammeyer-Mueller, J., Wanberg, C., Rubenstein, A., \& Song, Z. (2013). Support, undermining, and newcomer socialization: Fitting in during the first 90 days. Academy of Management Journal, 56(4), 1104-1124.

Kordić, B., \& Babić, L. (2014). Procena uspešnosti oblika socijalizacije novozaposlenih. Pedagogija, 69(3), 430-440.

Luthans, F., Avolio, B.J., Avey, J.B., \& Norman, S.M. (2007). Psychological capital: Measurement and relationship with performance and job satisfaction. Personnel Psychology, 60(3), 541-572.
Morrison, E.W. (2002). Newcomers' relationships: The role of social network ties during socialization. Academy of Management Journal, 45(6), 1149-1160.

Nigah, N., Davis., A.J., \& Hurrell, S.A. (2012). The impact of buddying on psychological capital and work engagement: an empirical study of socialization in the professional services sector. Thunderbird International Business Review, 54(6), 891-905.

Van Maanen, J. (1976). Breaking In: Socialization to Work. U R. Dubin (Ed.), Handbook of Work, Organization, and Society (pp. 67-130). Chicago: Rand-McNally. 